Available online @ https://jiem.jnnce.ac.in https:www.doi.org/10.37314/JJEM.2021.050207 Indexed in International Scientific Indexing (ISI) Impact factor: 1.395 for 2021-22 Published on: 31January 2022

\title{
The Evaluation of Requisites of Product Attributes in Virtual Education System
}

\author{
Karthik Gupta $\mathbf{P}^{1}, \quad$ Srikanth $\mathbf{C}^{2}$ \\ ${ }^{1}$ Edurite College of Management Studies, Shivamogga,Karnataka State, India \\ ${ }^{2}$ Department of Management Studies, \\ JNN College of Engineering, Shivamogga, Karnataka State, India \\ karthikgupt@gmail.com
}

\begin{abstract}
Education is the vital component of human living. Virtual structure of education and training is the foremost education method providing the finest educational services to the students with numerous attributes to enhance the knowledge of the students. This paper is based on the identifying the customers' requirement with respect to the product attributes of the virtual education system. The Product attributes of online education platform are bifurcated essentially in terms of Video Classes, Study Materials and Test with its Assessment. The study is conducted to understand the user requirement over the attributes of recorded classes, live classes, mock tests and its assessments and related to study materials. The requirement to deliver the quality of content using the different methodologies and technologies are analyzed and understood. The opinion over the different kinds of mock tests is very similar and lot of priority need to be provided for the development of live classes. Statistical tools are implemented in the study to comprehend the users' behavior and requisite towards the product attribute of virtual educational system. The study is accomplished with reference to the demographic factors of students in terms of age and different educational background.
\end{abstract}

Keywords: Virtual Educational System, Video Classes, Study Materials, Assessment of Tests

\section{Introduction}

Virtual platform is having a key scale by positioning its requisites in the minds of the students and their parents. Constructive development in the virtual education market made the students to have a diverse perception about the virtual education market with great involvement. The big players in the market are investing millions of American dollars to acquire the small virtual education service providers and acquiring major market share in virtual education platform. The involvement of edupreneurs in the educational market and the response by the students towards the virtual educational system is the key game changer in the educational industry. In the phase of 8 years, the dependency over the virtual education has augmented and variety of methodology has implemented in the market to provide better services to the students. Particularly the training based on only Recorded, Live sessions and both are having a different opinion from the student base. The combination of Live and Recorded sessions in the training part is the primary factor, web based education and mobile application based education is the part of human life in the present day. Augmented reality, video reality, artificial intelligence is the best technologies to develop the content and infrastructure of e - learning. Gamification of mock tests and computer based assessments has made learning more exciting and effectual. 


\section{Literature Review}

Immense Literature is reviewed to understand the nature of online education system and its methodology of working in the actual scenario. Ashley Babcock et al.,[1]: Hussey Researchers made an article regarding the identification of gap exists between the organization, faculties and students in an online learning center and analysed the actual reasons for it. There is shift in the paradigm of traditional teaching to virtual teaching. The adoptability of the new model is difficult and time consuming. Motivation is the major factor to bring the change. The existence of gap between the students and faculty are more compared to the gap exists between the organization and faculty. The researcher has provided the reasons to overcome from the existing problems. Esther Smidt et al., [2]: "The meaning of quality in an online course to administrators, faculty, and students" is the article published in the journal "Journal of Interactive Learning Research" is reviewed and analyzed the Faculty and students perceptions of online education with the study of methodology used to analyze the collected results. Live educational websites are reviewed and studied the adopted educational model to deliver the education to the students in the form of video classes, Study materials and Online Mock tests. Muhammad Amaad Uppal, Samnan Ali and Stephen R. Gulliver et al.,[3]: With the aid of ELQ model, the researcher has identified many factors to enhance the $\mathrm{e}-$ learning quality. In the present scenario, the shift towards $\mathrm{e}$ - learning is increasing day by day with lot of dependencies. Researcher has analyzed and identified to minimize the service gap between the $\mathrm{e}$ - learning service provider and the user of content to uplift the quality of the service. Uzodinma Phillip O [4]: The detail literature review is done to understand the requirement of online examination with the aid of tutor and the problems involved in implementing the online examination. The researcher is analyzed by allowing the students to register in the website to attend the online mock tests with the aid of tutor. Tutors have the access to view and edit the student profile. Questions can be uploaded by the instructor or any other authorized person during the time of mock tests. It is analyzed that, motivation is required for the tutors to adopt new system and guide the students to follow it. The researcher has identified the benefits such as save of time, save of cost, avoiding of malpractice and many more. Which eventually enhance the quality of the test. Implementation of computerized test will improve the quality of test need to be conducted save of time, save of cost, avoiding of malpractice and many more. Which eventually enhance the quality of the test. Implementation of computerized test will improve the quality of test need to be conducted. Alistair Sutcliffe [5]: The attractiveness of the website plays a vital role in the development of any websites. By conducting backhand analysis, the impact of attractiveness on users can be measured. The researcher has bifurcated the attractiveness into two generic qualities, such as aesthetic design including of brand image, messaging, visual aid, and content design to attract the users in an effective way. The researcher has identified the elements that impact on attractiveness of the web pages are like, use of color, design of layout, style and symmetry, choice of media and many more. The analysis part has proven that the attractiveness is the major factor for the development of site that makes the users to be in the website for the longer period.

\section{Objective of the Study}

1. To understand the preference of students on diverse product attributes of virtual education system.

2. To analyze the relationship between the Recorded Video classes and Live Video Classes, Mock test and its Assessment.

3. To understand the variation in the opinion provided by the students over the requirements of the attributes of virtual education with respect to its product attributes. 
4. To analyze the requirement of study materials in the present market condition.

\section{Data Collection, Analysis and Interpretation}

Primary data is collected at random through the structured questionnaire which is sent in Google forms by targeting the students of various educational streams in shimoga city. There are 12 questions in total including 7 demographical questions and remaining 5 questions are again bifurcated into $20 \mathrm{sub}$ questions to collect the ordinal data. Demographic section includes the questions related to Age, Educational Background, and few more. The other phase is considered to analyze the ordinal data that is completely related to the virtual educational attributes such as Video Classes, Study Materials and Mock tests with its assessment which are considered for the study. Questions are appropriately considered to understand the preference of students on diverse product attributes of virtual education system, to analyze the relationship between the Recorded Video classes and Live Video Classes, Mock test and its Assessment. The existing Gap is also measured in terms of product features. A feature related to the normal offline learning is also considered to measure its importance after implementing in the virtual educational platform. A total of 162 students are participated in the survey with different educational backgrounds.

Highest number of respondents belongs to the age group of 18 years to 22 years striking $66 \%$ of the total respondents. The male respondents and female respondents are equal in number with 13 different educational backgrounds. Among 162 respondents $60.3 \%$ are preferring both web based and mobile application based educational platform, $28.2 \%$ and $11.5 \%$ respondents are preferring mobile application based learning and web based learning respectively.

The highest weighted average is calculated for the attributes related to Recorded Video Classes, Live Video Classes, Mock Tests,
Assessment of Mock Test and Study Materials.

The highest Weighted Average of the above mentioned attributes are shown in Table 1.

The attributes mentioned in Table 1 are having highest weighted average representing the highest requirement of attributes by the respondents. Among the obtained highest weighted average, High Quality Video is very much preferable in the recorded session. According to the present scenario, there is a lack of availability of the internet in many rural areas and hence to provide high quality of the videos, high speed of internet is very important and hence infrastructure developments need to be prioritized.

The standard deviation of the attributes considered for the survey are shown in Table 2.

The calculated standard deviation represents the study materials attribute is having least standard deviation with very least coefficient of Variation. That is 0.570 and $1.37 \%$ respectively. This indicates, the opinion of the surveyed respondents over the sub attributes of study materials are almost same and almost equal priority is provided. The next least coefficient of variation is $5.47 \%$ representing the least variation among the sub attributes of mock tests. Awareness level of verities of mock tests and its requirement is known to the respondents and hence the conducting of mock tests in different situation and in different phases will be easy. The attribute Recorded classes, is having the coefficient of variation $7.436 \%$, indicates some measures need to be taken to create the awareness among the availability of the different verities of recorded session and its usages. Evaluation and assessment is having a $30.43 \%$ of coefficient of variation that indicates some the variation in the opinion of the respondents over the methodology inculcated to evaluate the test results. The attributes of live classes are having the coefficient of variation as $61.80 \%$, indicates the respondents are having very 
different opinion about their requirements and its usage.

Table 1: The highest Weighted Average of the above mentioned attributes

\begin{tabular}{|c|l|c|}
\hline Sl. No & \multicolumn{1}{|c|}{ Attributes } & $\begin{array}{c}\text { Highest } \\
\text { Weighted } \\
\text { Average }\end{array}$ \\
\hline 1. & Recorded Video Classes - High Quality Video is very much preferable & 43.33 \\
\hline 2. & $\begin{array}{l}\text { Live Video Classes - Additional supporting content like PDF, PPT, Word } \\
\text { DOCS, and Excel Sheets are to be provided along with the Live Classes. }\end{array}$ & 42.46 \\
\hline 3. & $\begin{array}{l}\text { Mock Tests - Cheating proof - Time Limit is required to every test to } \\
\text { avoid cheating }\end{array}$ & 40.66 \\
\hline 4. & $\begin{array}{l}\text { Assessment of Mock Tests - I prefer the results of the test should be } \\
\text { provided in the form of obtained percentage, percentile, average Score } \\
\text { and overall score }\end{array}$ & 39.26 \\
\hline 5. & $\begin{array}{l}\text { Study Materials - Platform should be provided to learn about new tech- } \\
\text { nologies, along with its uses. }\end{array}$ & 42.133 \\
\hline
\end{tabular}

Table 2: The standard deviation of the attributes considered for the survey

\begin{tabular}{|c|c|c|c|}
\hline Sl.No & Attributes & Standard Deviation & $\begin{array}{c}\text { Coefficient of } \\
\text { Variation }\end{array}$ \\
\hline 1. & Recorded Video Classes & 2.89 & $7.436 \%$ \\
\hline 2. & Live Video Classes & 23.37 & $61.80 \%$ \\
\hline 3. & Mock Tests & 2.09 & $5.47 \%$ \\
\hline 4. & Assessment of Mock Tests & 11.24 & $30.43 \%$ \\
\hline 5. & Study Materials & 0.570 & $1.37 \%$ \\
\hline
\end{tabular}

The relationship between the Recorded classes and live classes is -0.8325 , representing a very low degree of negative correlation exist between the attributes of recorded classes and attributes of live classes. Positive correlations of 0.5672 exist between the attributes of mock test and its types of assessments. Representing a moderate relationship exist between those two attributes.

\section{Suggestions}

6.1 Respondents prefer high quality of recorded classes with the usage of info - graphics, VFX's Demo videos, studio setup and motion design videos. Recorded session without instructor and a voice over is very much least preferred. Inculcating of graphics, vfx and motion design. Usage of augmented and video reality will enhance the quality of recorded session and it is primarily required in the present scenario.

6.2 Smaller recorded videos and division of major portion of videos in to smaller portions are always preferable and it is suggested to develop the smaller videos covering the required concept in that particular video.

6.3 A very low degree of correlation exists between the attributes of Recorded classes and live classes. There is a mixed opinion among the attributes of the live classes from the respondents and hence lot of awareness need to be provided to the students. Live classes conducted through web cam and using normal camera is not very effective compared to the usage of info - graphic styles and power point presentation in the live video classes. 
Priority has to be provided for the implement of new technology and usage of new technical infrastructure for the betterment of live classes and to enhance the quality.

6.4 The usage of general live streaming method in the classroom setup and the implementation of basic technical facilities in the conducting of live videos have to be avoided in general and advanced techniques are to be preferred to enhance the quality of teaching.

6.5 The requirements of all the variety of mock tests are similar and based on the technical feasibility and necessity for the test takers, the conducting of different type of mock test is preferred.

6.6 Demo version to access the study material is very much preferred and the quality of materials can be decided before the usage of it.

\section{References}

1. Ashley Babcock, Tara Lehan and Heather D. Hussey. (2019). Mind the Gaps: An Online Learning Center's Needs Assessment. TLAR, Vol. 24, No.1, September 2019, pp. 27 - 58. https://files.eric.ed.gov/fulltext/EJ1214728.pdf

2. Esther Smidt, Rui Li, Jennifer Bunk, Timothy Kochem and Ashley Mcandrew, The Meaning of Quality in an Online Course to Administrators, Faculty, and Students, Journal of Interactive Learning Research, Vol. 28, No.1, 2017, pp. 65-86.

3. Muhammad Amaad Uppal, Samnan Ali and Stephen R. Gulliver, (2017) Factors determining e-learning service quality, British Journal of Educational Technology, Vol. 1, No. 1, 2017, pp.1 - 15.

https://www.researchgate.net/publication/3154 16635_Factors_determining_elearning_service_quality_ELQ factors
4. Uzodinma Phillip O, Problems Of Online Examinations and Tutor-Marked Assignment (TMA), July 2015. Researchgate.com. https://www.researchgate.net /publication / 306118684_PROBLEMS_OF_ONLINE_EXA MINATIONS_AND_TUTORMARKED_ASSIGNMENT_TMA

5. Alistair Sutcliffe, Assessing the Reliability of Heuristic Evaluation for Website Attractiveness and Usability, Centre for HCI Design, Department of Computation, UMIST, UK, Proceedings of the 35th Hawaii International Conference on System Sciences, Jan. 72002 to Jan. 10 2002. Big Island, Hawaii.

http://citeseerx.ist.psu.edu/viewdoc/download? $\mathrm{doi}=10.1 .1 .545 .6310 \& \mathrm{rep}=$ rep $1 \&$ type $=\mathrm{pdf}$

6. India Today Web Desk, New Delhi, 6 technology trends that pushing up digital education in India, 8-August-2017

https://www.indiatoday.in /educationtoday/featurephilia/story/digital-education1027965-2017-08-08

7. Panopto, 4 Types of Videos For More Engaged eLearning, 19 March 2019, https://www.panopto.com/blog/4-types-ofvideos-for-more-engaged-e-learning/

8. Corentin Sannié, 3 Different Types Of Online Training Videos, 13 April 2018, https://elearningindustry.com/online-trainingvideos-3-different-types

9. Tech smith, 5 Types of Instructional Videos and When to Use Them, https://www.techsmith.com/blog/types-of-

instructional-videos/

10. Team Knorish, Types of Video Production You Can Consider For The Next Online Course

https://blog.knorish.com/2020/04/02/types-ofvideo-production-online-courses

11. Sara Mcguire, , 10 Types of Visual Aids For Learning [+ Teaching Aid Templates \}, Sep 28, 2018 
https://venngage.com/blog/visual-aids-forlearning-templates/

12 Chanakya IAS Academy Nurturing Leaders of Tomorrow, 5 Advantages of Online Mock Tests, December 23, 2017, https://elearningindustry.com/online-mocktests-5-advantages
13. Knowly, Types of exams and tests, July 22, 2020.

https://www.onlineexambuilder.com/knowledg e-center/exam-knowledge-center/types-ofexams-and-tests/item 10246 